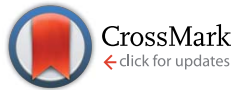

Cite this: RSC Adv., 2017, 7, 1504

Received 13th October 2016 Accepted 6th December 2016

DOI: 10.1039/c6ra25183h

www.rsc.org/advances

\section{Lipase-catalyzed modification of natural Sapium sebiferum oil-based polyol for synthesis of polyurethane with improved properties}

\begin{abstract}
Guiying Wu, Xin He and Yunjun Yan*
Polyols are one of the dominant reactants in polyurethane (PU) synthesis. However, polyols from Sapium sebiferum oil prepared by epoxidation-hydroxylation have an inferiority of secondary alcohol groups and large non-functional branches. Their lower reactivity, which in turn limits the properties of the generated $\mathrm{PU}$. In this study, the optimal reaction conditions for the synthesis of polyols with primary alcohol groups by lipase hydrolysis have been investigated by single factorial experiments and response surface methodology. The optimized conditions for lipase hydrolysis were identified as a molar ratio of $2.2: 1$, a reaction time of $11.2 \mathrm{~h}$, and a temperature of $47.2^{\circ} \mathrm{C}$. The highest hydroxyl value of the obtained polyol with primary alcohol groups reached $211 \mathrm{mg} \mathrm{KOH} \mathrm{per} \mathrm{g.} \mathrm{Furthermore,} \mathrm{a} \mathrm{novel} \mathrm{PU} \mathrm{was}$ successfully synthesized from the synthetic polyol and isophorone diisocyanate by an in situ polymerization method. The generated PU showed a glass transition temperature of $60.6{ }^{\circ} \mathrm{C}$, an initial decomposition temperature of $307.2{ }^{\circ} \mathrm{C}$, a tensile strength of $12.5 \mathrm{MPa}$, and a Young's modulus of 22.3 MPa. These good thermal and mechanical properties of the PU prepared from the modified polyol by lipase hydrolysis can be attributed to its greater number of chemical interactions and cross-linked networks.
\end{abstract}

\section{Introduction}

Polyurethanes (PUs), after about 70 years of development, have become one of the most dynamic groups of polymers, exhibiting versatile properties suitable for practical use in all fields of polymer applications, such as foams, elastomers, thermoplastics, adhesives, coatings, sealants, fibers, and so on. ${ }^{1}$ PUs are usually obtained by reaction of an oligomeric polyol derived from petroleum and a diisocyanate (or polyisocyanate). Because of significant fluctuations in the crude oil market and unsustainable development, there has been much recent interest from the chemical industry in the production of bio-based polyols, which are mainly synthesized from vegetable oils. ${ }^{2}$ The markets for vegetable oil-based polyols are growing due to economic, environmental, and sustainability advantages. ${ }^{3}$

Sapium sebiferum (Chinese tallow tree) is one of the four major woody oil trees in China, and provides excellent and abundant biomass. ${ }^{4}$ The trees can grow rapidly and reach maturity within approximately 3-4 years, and generate economic yields in its productive life span of which ranges between 70 and 100 years. Also the trees can be cultivated in marginal land and non-agricultural areas with low fertility and

Key Laboratory of Molecular Biophysics of the Ministry of Education, College of Life Science and Technology, Huazhong University of Science and Technology, Wuhan 430074, China. E-mail: yanyunjun@hust.edu.cn; Fax: +86-27-87792213; Tel: +86$27-87792213$ moisture demand. Moreover, they have huge potential to restore degraded lands, create rural employment generation and fixing of up to $\mathrm{CO}_{2}$ emissions. ${ }^{5}$ Sapium sebiferum oil (SSO) as an industrial resource can avoid competition with human food supplying, because they are not suitable for human food due to the presence of some toxic components in the oil. ${ }^{6}$ Therefore, SSO is one of the most suitable platform feedstock for the production of polyols and PUs.

A polyol bearing a primary alcohol group is usually three times more reactive towards isocyanate than one bearing a secondary alcohol group. ${ }^{7}$ Typical SSO-based polyols have secondary alcohol groups derived from epoxide ring-opening reaction near the middle of the fatty acid chain. Partial hydrolysis by lipase to afford primary alcohol groups could improve the reactivity of SSO-based polyols. Therefore, lipase hydrolysis has been applied to increase the number of primary alcohol groups in SSO-based polyols and replace the undesirable saturated fatty acid moieties. Lipases are renewable biocatalysts broadly employed in the transformation of lipids, especially in food, detergent, oil processing, biodiesel preparation, and many other biosynthetic industries. ${ }^{8}$ They offer high stereoselectivity and regioselectivity, but this depends on enzyme structure, substrate structure, factors affecting binding of the enzyme to the substrate, and other factors influencing the enzyme activity. ${ }^{9}$

The objective of this study is to propose the generation of new SSO-based polyols by two sequential steps of epoxidation- 
hydroxylation and lipase partial hydrolysis with a selected C. rugosa lipase. The resulting SSO-derived polyol bearing primary alcohol groups should be suitable for the synthesis of PU with improved properties.

\section{Materials and methods}

\subsection{Materials}

SSO was purchased from a refinery factory in Dawu County (Hubei Province, China). C. rugosa lipase was bought from Sigma-Aldrich (Shanghai, China) and used without further purification. Isophorone diisocyanate (IPDI) was obtained commercially from Aladdin Chemistry Ltd. Co. (China). Peracetic acid, acetic acid, methanol, fluoroboric acid, chloroform, and acetone were obtained from Sinopharm Chemical Reagent Ltd. Co. (Shanghai, China). Polyols prepared from SSO were dried at $60{ }^{\circ} \mathrm{C}$ for $12 \mathrm{~h}$ under vacuum to remove moisture.

\subsection{Synthesis methods}

2.2.1 Preparation of polyol by epoxidation-hydroxylation. The polyol was generated from SSO in a continuous process of epoxidation-hydroxylation to avoid unnecessary intermediate steps. ${ }^{10}$ First, SSO (20 g) was placed in a $500 \mathrm{~mL}$ four-necked round-bottomed flask equipped with a thermometer, a dropping funnel, and a mechanical stirrer. A solution of peracetic acid in acetic acid was dropped into the oil at $10{ }^{\circ} \mathrm{C}$, maintained by means of an ice-bath. The mixture was stirred at $25^{\circ} \mathrm{C}$ for $5 \mathrm{~h}$ to afford a solution of the epoxidized oil product in acetic acid. Methanol and fluoroboric acid were placed in a $500 \mathrm{~mL}$ threenecked round-bottomed flask at room temperature. The prepared epoxidized SSO was then dropped into the methanol/ fluoroboric acid solution to give a molar ratio of methanol to SSO of $10: 1$ and a fluoroboric acid loading of $0.4 \mathrm{wt} \%$ with respect to $\mathrm{SSO}$, and the mixture was stirred at $55{ }^{\circ} \mathrm{C}$ for $0.5 \mathrm{~h}$. After the solution had cooled, water $(100 \mathrm{~mL})$ and chloroform $(50 \mathrm{~mL})$ were added. After a certain time, the organic and aqueous layers were separated. The organic phase was then washed with deionized water until the washings were neutral.
The solvent was removed under vacuum to leave a yellow oily material. The polyol product showed an -OH number of $143 \mathrm{mg}$ $\mathrm{KOH}$ per $\mathrm{g}$, and was thus designated as polyol-143.

2.2.2 Modification of polyol-143 by lipase hydrolysis. The aforementioned obtained polyol-143 was partially hydrolyzed by C. rugosa lipase without any surfactant or organic solvent (as shown in Scheme 1). By following the progress of the reaction, a single factorial experiment was first designed, and then response surface methodology (RSM) was adopted to further optimize the principal parameters. ${ }^{\mathbf{4 , 1 1}}$

Hydrolysis of polyol-143 with distilled water $\left(\mathrm{H}_{2} \mathrm{O}\right)$ was carried out using $C$. rugosa lipase as catalyst in a $50 \mathrm{~mL}$ flask, which was placed in a thermostatted shaking bed with a temperature monitor. The agitation rate was set at $200 \mathrm{rpm}$. The components of polyol- $143, \mathrm{H}_{2} \mathrm{O}$, and C. rugosa lipase ( $5 \mathrm{wt} \%$ loading of polyol-143) were allowed to react under certain conditions. Specifically, the effects of reaction temperature $\left(30-65{ }^{\circ} \mathrm{C}\right)$, reaction time $(1-13 \mathrm{~h})$, and molar ratio of $\mathrm{H}_{2} \mathrm{O}$ to polyol-143 (1:1-5:1) on the hydrolysis were explored, and the increased hydroxyl value of the produced polyol was chosen as an indicator.

After reaction, the product was partitioned between suitable volumes of aqueous $\mathrm{Na}_{2} \mathrm{CO}_{3}$ solution (0.5 M, pH 11.0) and diethyl ether in a separating funnel. The mixture was left overnight, and then high-speed centrifugation was applied to help separate the fatty acid from the organic phase. Free fatty acids were in the aqueous phase, whereas ester glycerides were in the organic phase. Finally, diethyl ether was removed from the organic phase at $50{ }^{\circ} \mathrm{C}$. The obtained ester glycerides (the polyol product) showed a hydroxyl value of $211 \mathrm{mg} \mathrm{KOH} / \mathrm{g}$, and the sample was designated as polyol-211.

2.2.3 Synthesis of PU from the modified polyol-211. SSO-based PUs were synthesized by the reaction of IPDI and SSO-based polyols according to previously reported methods. ${ }^{10,12}$ The PUs prepared from polyol-143 and polyol-211 were designated as PU143 and PU211, respectively. The synthetic route to PU211 is shown in Scheme 2. The polyols and IPDI (1.1 : 1 molar ratio of -NCO to -OH groups) were allowed to

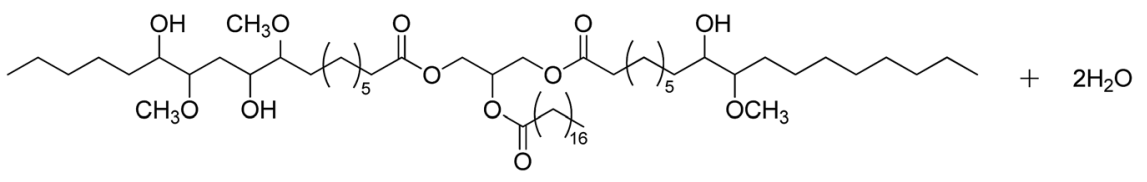

polyol-143<smiles></smiles>

Lipase

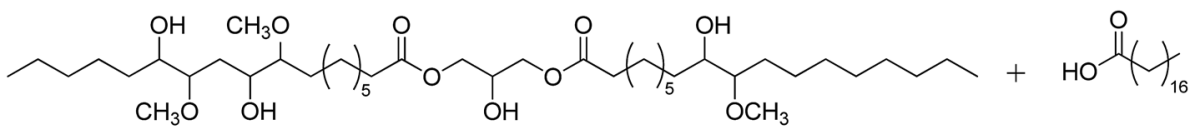

polyol-211 

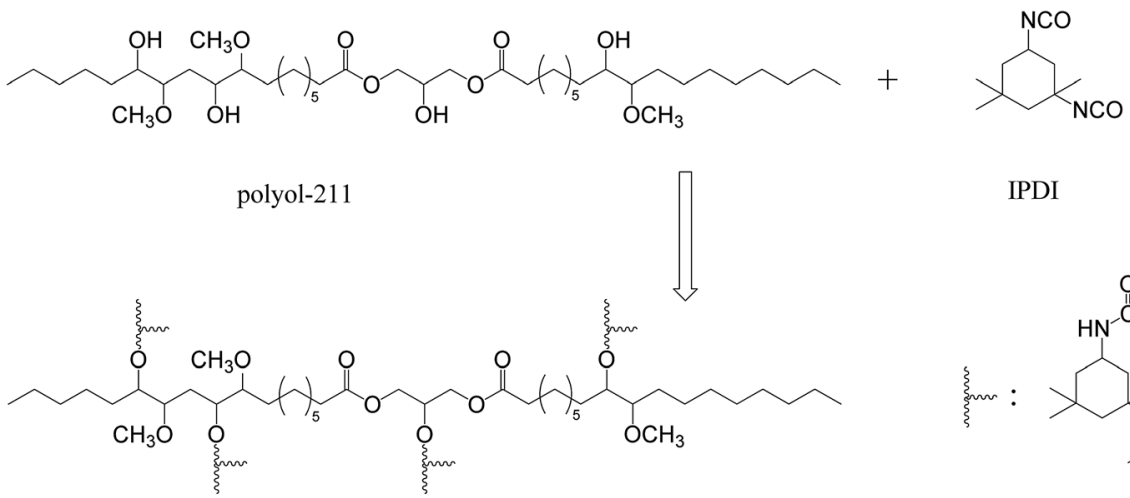

IPDI

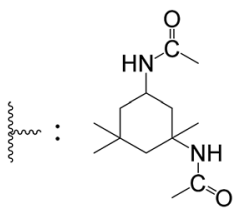

PU211

Scheme 2 Synthesis of PU211 from the modified polyol-211.

react with magnetic stirring under a $\mathrm{N}_{2}$ atmosphere in a flask fitted with a water-cooled condenser at $60^{\circ} \mathrm{C}$. During this stage, acetone was added to reduce the viscosity of the system. After reaction for $2 \mathrm{~h}$, the respective products were degassed under vacuum for $10 \mathrm{~min}$, poured onto a sheet of release paper, and then heated in an oven at $60{ }^{\circ} \mathrm{C}$ for $24 \mathrm{~h}$ to complete the reactions. The samples were then allowed to cool to room temperature and were demolded.

\subsection{Testing and measurement}

Acid value is an important index for evaluation of vegetable oilbased polyols. Their values were determined through standard test GB/T5530-2005 with some modifications. The acid value is used to determine polyols' equivalent weight by the following equation:

$$
\text { Acid equivalent weight }=\frac{56.1 \times 1000}{\text { acid value }(\mathrm{mg} \mathrm{KOH} \text { per g })}
$$

Hydroxyl value is one of the most important properties of polyols indicating numbers of hydroxy functional groups per gram of polyols. The number is evaluated according to HG/T 2709-95 to determine hydroxyl numbers of polyols. The hydroxyl value is also used to determine polyols' equivalent weight by the following equation:

Hydroxyl equivalent weight $=\frac{56.1 \times 1000}{\text { hydroxyl value }(\mathrm{mg} \mathrm{KOH} \mathrm{per} \mathrm{g)}}$

For the experimental data, average value $x_{i}$ are calculated. $x_{i}=\frac{\sum_{j=1}^{n} y_{i}}{n}, y$ is the experimental data, $n$ is the repeated experimental times, $j$ for every experiment point, $i$ with different samples synthesized in the same condition, which is 3 during

our calculation. Standard deviation $\sigma: \sigma_{x_{i}}=\sqrt{\frac{\sum_{j=1}^{n_{i}}\left(y_{i j}-x_{i}\right)^{2}}{n-1}}$.
The Gel Permeation Chromatography (GPC) set-up was equipped with a refractive index detector and a pillar-type PL gel $5 \mu \mathrm{m}$ MIXED-C $300 \times 7.5 \mathrm{~mm}$ column. The column temperature and pressure were $40{ }^{\circ} \mathrm{C}$ and $6.86 \mathrm{MPa}$, respectively. Tetrahy-

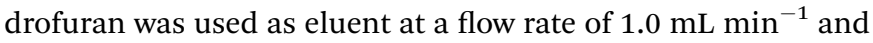
polystyrene standards (SHODEX SL-105) were used as standard sample.

To examine the significant absorption bands of the PUs, Fourier-transform infrared (FTIR) spectra of the samples in the wavenumber range, $\nu=4000-400 \mathrm{~cm}^{-1}$ were obtained at a resolution of $4 \mathrm{~cm}^{-1}$ on Bruker Vertex 70 FTIR spectrometer at room temperature.

To investigate the thermal stabilities of the PUs, thermogravimetric analysis (TGA) was performed on a Pyris 1 TGA instrument. Samples (ca. $5 \mathrm{mg}$ ) were heated from 50 to $600{ }^{\circ} \mathrm{C}$ at a rate of $10{ }^{\circ} \mathrm{C} \min ^{-1}$ in a nitrogen atmosphere.

The glass transition temperature $\left(T_{\mathrm{g}}\right)$ of the PU was determined by differential scanning calorimetry (Diamond DSC) from 10 to $150{ }^{\circ} \mathrm{C}$ at a heating rate of $10{ }^{\circ} \mathrm{C} \mathrm{min}{ }^{-1}$ under nitrogen flow, which is a midpoint temperature between extrapolated onset temperature and extrapolated end temperature.

The mechanical properties of the PU films $(100 \mathrm{~mm} \times 10$ $\mathrm{mm} \times 1 \mathrm{~mm})$ were tested on a CMT4104 universal testing machine (Shenzhen SANS Testing Machine Ltd. Co., Shenzhen, China) at a speed of $50 \mathrm{~mm} \min ^{-1}$. For each sample, five specimens were tested, and the average value was calculated.

\section{Results and discussion}

\subsection{Lipase-catalyzed synthesis of polyols with primary alcohol groups}

\subsubsection{Single factorial experiments}

3.1.1.1 Effect of molar ratio of $\mathrm{H}_{2} \mathrm{O}$ to polyol-143. All three polyol-143 samples were lipase hydrolyzed in the same experimental conditions of $5 \mathrm{wt} \%$ enzyme dosage, rotate speed of $200 \mathrm{rpm}$, the reaction time of $10 \mathrm{~h}$ and the reaction temperature of $45{ }^{\circ} \mathrm{C}$. The effect of molar ratio of $\mathrm{H}_{2} \mathrm{O}$ and polyol-143 on the increased hydroxyl value was studied. It can be seen from Fig. 1 


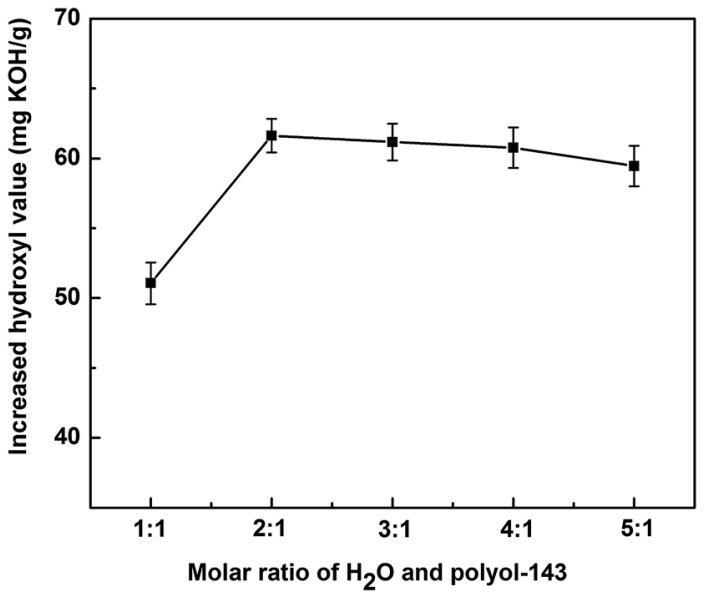

Fig. 1 Effect of molar ratio of $\mathrm{H}_{2} \mathrm{O}$ to polyol-143 on increased hydroxyl value.

that in the range from $1: 1$ to $5: 1$, increasing $\mathrm{H}_{2} \mathrm{O}$ content initially improves the hydroxyl value of the polyol, but that excess $\mathrm{H}_{2} \mathrm{O}$ decreases this value. It can be deduced that increasing the water content in the system can reduce its viscosity and promote the catalytic efficiency of the lipase. However, with excessive $\mathrm{H}_{2} \mathrm{O}$ amount, the low concentration of reactant could reduce the reaction rate. It is also possible that too much hydrolysis will produce a certain amount of glycerols, which are then lost into the aqueous phase during the purification. Therefore, the maximum hydroxyl value was achieved at a molar ratio of $\mathrm{H}_{2} \mathrm{O}$ to polyol-143 of $2: 1$.

3.1.1.2 Effect of reaction time. All three polyol-143 samples were lipase hydrolyzed in the same experimental conditions of 5 wt $\%$ enzyme dosage, $200 \mathrm{rpm}$ rotate speed, $45{ }^{\circ} \mathrm{C}$ reaction temperature, $2: 1$ for the molar ratio of $\mathrm{H}_{2} \mathrm{O}$ to polyol-143. The effect of the reaction time on the increased hydroxyl value was studied. As shown in Fig. 2, during reaction for $11 \mathrm{~h}$, the hydroxyl value of the polyol first showed a significant increase and then a maximum was attained. On extending the reaction time to $13 \mathrm{~h}$, there was a downward trend in the hydroxyl value. It could be deduced that with extension of the reaction time, the

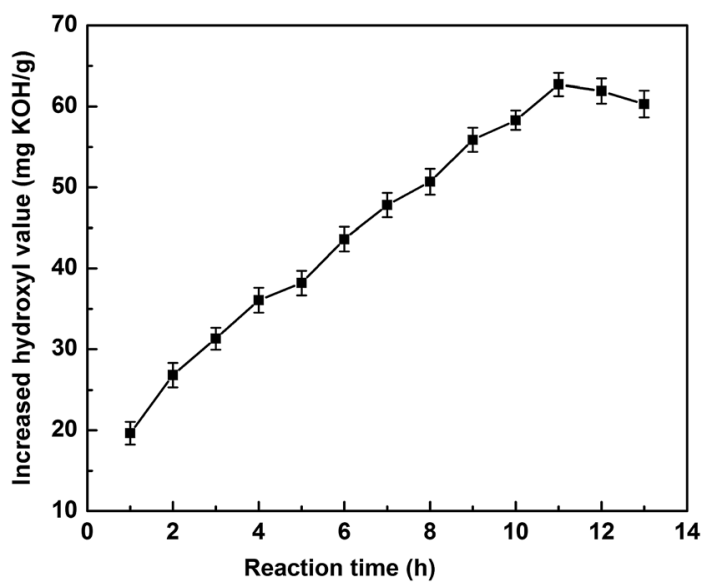

Fig. 2 Effect of reaction time on increased hydroxyl value.

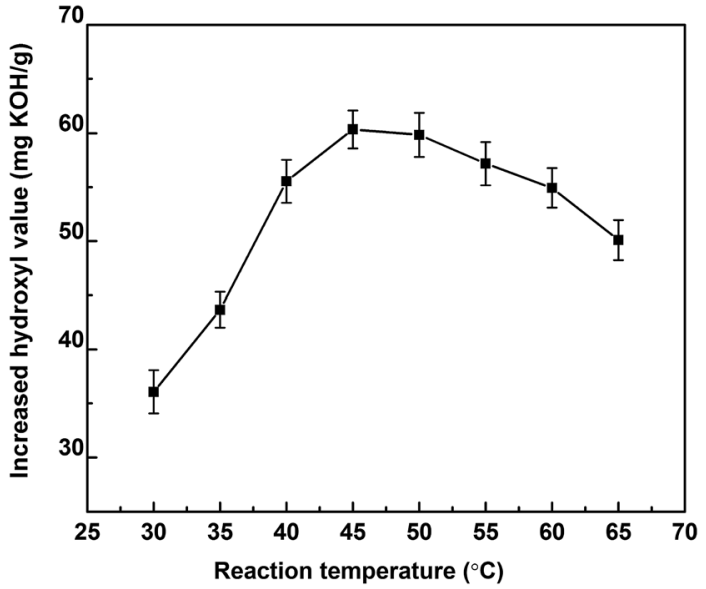

Fig. 3 Effect of reaction temperature on increased hydroxyl value.

complete hydrolization of the three ester bond of triglycerides with a certain amount would produces glycerols, which can be dissolved in the water. Therefore, after high-speed centrifugation, the hydroxyl value of the polyol in the oil phase was slightly decreased.

3.1.1.3 Effect of reaction temperature. All three polyol-143 samples were lipase hydrolyzed in the same experimental conditions of $5 \mathrm{wt} \%$ enzyme dosage, $200 \mathrm{rpm}$ rotate speed, $11 \mathrm{~h}$ reaction time, 2 : 1 molar ratio of $\mathrm{H}_{2} \mathrm{O}$ to polyol-143. The effect of reaction temperature on the hydrolysis was investigated in the range from 30 to $65{ }^{\circ} \mathrm{C}$ (as shown in Fig. 3). The maximum hydroxyl value was obtained at $45{ }^{\circ} \mathrm{C}$. On further increasing the reaction temperature, a decreasing trend was observed. For this reaction, temperature is effectively a double-edged sword. On the one hand, higher temperature would improve the reaction rate. On the other hand, an excessively high temperature will reduce the enzyme activity and cause oligomerization of the polyol.

\subsubsection{Parameters optimized in the RSM}

3.1.2.1 Experimental design of the RSM. In order to further optimize the reaction parameters for polyol synthesis, a RSM experiment was designed according to the Box-Behnken model based on the above single factorial experiments., ${ }^{\mathbf{8 1 3 , 1 4}}$ A threefactor, three-level design that addressed the effects of molar ratio of $\mathrm{H}_{2} \mathrm{O}$ to polyol-143, reaction time, and reaction temperature on the increased hydroxyl value of polyols was selected. The RSM experimental design is presented in Table 1 . The experimental increased hydroxyl value responses obtained at the design points are illustrated in Table 2. Fifteen experiments were included in the design, and the results were analyzed with multiple regressions using SAS 9.2 software.

The model for the increased hydroxyl values of the polyols was regressed, and can be expressed as follows (in terms of coded levels):

$$
\begin{gathered}
Y_{1}=-1859.61+58.4625 X_{1}+245.875 X_{2}+20.6725 X_{3}- \\
4.3625 X_{1} X_{1}-2.7 X_{1} X_{2}-0.195 X_{1} X_{3}-11.2875 X_{2} X_{2}+0.27 X_{2} X_{3} \\
-0.2465 X_{3} X_{3}
\end{gathered}
$$


Table 1 The experimental design of RSM

\begin{tabular}{lllll}
\hline $\begin{array}{l}\text { Independent } \\
\text { variables }\end{array}$ & Symbols & $\begin{array}{l}-1 \\
\text { (low level) }\end{array}$ & $\begin{array}{l}0 \\
\text { (mid-level) }\end{array}$ & $\begin{array}{l}1 \\
\text { (high Level) }\end{array}$ \\
\hline $\begin{array}{l}\text { Molar ratio } \\
\left(\mathrm{mol} \mathrm{mol}^{-1}\right)\end{array}$ & $X_{1}$ & 1 & 2 & 3 \\
$\begin{array}{l}\text { Time }(\mathrm{h}) \\
\text { Temperature }\left({ }^{\circ} \mathrm{C}\right)\end{array}$ & $X_{2}$ & 10 & 11 & 12 \\
& $X_{3}$ & 40 & 45 & 50
\end{tabular}

Table 2 The experimental results of RSM

\begin{tabular}{lllll}
\hline No. & $X_{1}$ & $X_{2}(\mathrm{~h})$ & $X_{3}\left({ }^{\circ} \mathrm{C}\right)$ & $Y_{1}(\mathrm{mg}$ KOH per $\mathrm{g})$ \\
\hline 1 & 1 & 10 & 45 & 39.6 \\
2 & 1 & 12 & 45 & 55.8 \\
3 & 3 & 10 & 45 & 51.3 \\
4 & 3 & 12 & 45 & 56.7 \\
5 & 2 & 10 & 40 & 41.9 \\
6 & 2 & 10 & 50 & 49.8 \\
7 & 2 & 12 & 40 & 45.6 \\
8 & 2 & 12 & 50 & 58.9 \\
9 & 1 & 11 & 40 & 47.7 \\
10 & 3 & 11 & 40 & 53.5 \\
11 & 1 & 11 & 50 & 60.4 \\
12 & 3 & 11 & 50 & 62.3 \\
13 & 2 & 11 & 45 & 66.7 \\
14 & 2 & 11 & 45 & 67.3 \\
15 & 2 & 11 & 45 & 65.5 \\
\hline
\end{tabular}

Table 3 lists details of the ANOVAs and fitting statistics for the regression model. The regression equation obtained from the ANOVA yielded a $R^{2}$ (multiple correlation coefficient) of $98.68 \%$ (a value $>0.75$ confirms fitness of the model), confirming the validity of the model. Furthermore, the ANOVA analysis also provided a $P$-value for the model $(0.0004)$ and for lack of fit (0.1701), suggesting that the experimental data were well fitted by the model. The results indicated that the model terms $X_{1}, X_{2}$, $X_{3}, X_{1}{ }^{2}, X_{2}{ }^{2}$, and $X_{3}{ }^{2}$ were significant $(P<0.05)$.

The overall effects of the reaction factors at each level and the responses could be clearly understood from the set of surface plots and contour plots (see Fig. 4).

3.1.2.2 Validation of the RSM model. The optimized reaction conditions estimated through the model were a molar ratio of $\mathrm{H}_{2} \mathrm{O}$ to polyol-143 of $2.2: 1$, a reaction time of $11.2 \mathrm{~h}$, and a reaction temperature of $47.2{ }^{\circ} \mathrm{C}$. Triplicate experiments were then conducted under the optimal conditions to validate the precision of the RSM model. The increased hydroxyl value of the polyol was $67.9 \mathrm{mg} \mathrm{KOH}$ per g, which perfectly coincided with the model predicted value of $68.3 \pm 0.9$. Thus, the developed model was accurate and suitable for predicting the hydroxyl value of the polyol.

3.1.3 The basic characteristics of the polyols. The SSObased polyol-143 was partially hydrolyzed with C. rugosa lipase, and then a two-phase separation was performed with aqueous $\mathrm{Na}_{2} \mathrm{CO}_{3}$ solution (0.5 M, pH 11.0). The measured basic characteristics of the polyol products are listed in Table 4.
Table 3 ANOVA and fit statistics of RSM

\begin{tabular}{lccccl}
\hline Source & DF & SS & MS & F & Pr $>$ F \\
\hline$X_{1}$ & 1 & 51.51125 & 51.51125 & 17.92007 & $0.0082^{a}$ \\
$X_{2}$ & 1 & 147.92 & 147.92 & 51.45938 & $0.0008^{a}$ \\
$X_{3}$ & 1 & 227.9113 & 227.9113 & 79.28727 & $0.0003^{a}$ \\
$X_{1} X_{1}$ & 1 & 70.26981 & 70.26981 & 24.44592 & $0.0043^{a}$ \\
$X_{1} X_{2}$ & 1 & 29.16 & 29.16 & 10.14437 & $0.0244^{a}$ \\
$X_{1} X_{3}$ & 1 & 3.8025 & 3.8025 & 1.322839 & 0.3021 \\
$X_{2} X_{2}$ & 1 & 470.4283 & 470.4283 & 163.6557 & $<0.0001^{a}$ \\
$X_{2} X_{3}$ & 1 & 7.29 & 7.29 & 2.536093 & 0.1721 \\
$X_{3} X_{3}$ & 1 & 140.2206 & 140.2206 & 48.78086 & $0.0009^{a}$ \\
Model & 9 & 1078.381 & 119.8201 & 41.6838 & 0.0004 \\
Linear & 3 & 427.3425 & 142.4475 & 49.55557 & 0.0004 \\
Quadratic & 3 & 610.7858 & 203.5953 & 70.82807 & 0.0002 \\
Cross product & 3 & 40.2525 & 13.4175 & 4.667768 & 0.0652 \\
Error & 5 & 14.3725 & 2.8745 & & \\
Lack of fit & 3 & 12.6925 & 4.230833 & 5.036706 & 0.1701 \\
Pure error & 2 & 1.68 & 0.84 & & \\
$R^{2}=$ 98.68\% & & & & & \\
${ }^{a}$ Significant at 5\% level. & & &
\end{tabular}

C. rugosa lipase contains tunnel-like binding sites and prefers to bind to straight chain fatty acids rather than to bulky substrates. ${ }^{15}$ The fatty acid moieties with secondary alcohol groups on polyol-143 tend to bend and be bulky, and saturated fatty acid groups can probably fit more easily and rapidly into the active sites of $C$. rugosa lipase. Therefore, lipase partial hydrolysis can remove the undesirable saturated fatty acid moieties from polyol-143, and tends to produce a certain amount of primary alcohol groups.

The C. rugosa lipase powder solid from Sigma Aldrich contain not only the lipase catalyst, but also other auxiliary components such as enzyme stabilizer, inhibitor and preservative, which can inhibit the inactivation and oxidation of enzyme. After the lipase-catalyzed hydrolysis reaction, the product was treated by high speed centrifugation, but there were still some enzyme auxiliary agent residues in the ether phase. Therefore, the obtained polyol-211 had a greater viscosity and a lower molecular weight, compared to polyol-143.

High acid value of the polyol obtained by lipase hydrolysis can prolong reaction times in PU synthesis, as the carboxylic groups will undesirably consume isocyanates, forming unstable anhydrides. ${ }^{7}$ The high acid number product was therefore subjected to a washing step to remove most of the hydrolyzed acid groups and to reduce the acid number. $\mathrm{Na}_{2} \mathrm{CO}_{3}$ solution with $\mathrm{pH}$ in the range $11.0-13.0$ could effectively saponify and remove most of the fatty acids in the ester glyceride phase. ${ }^{16}$

3.1.4 Synthesis of SSO-based PU. Plant oils are a rich source of polymer precursors that can be modified to exhibit various types of functionalities, leading to new PU materials with a wide range of properties from structural to functional. ${ }^{17} \mathrm{SSO}$, as a non-edible drying oil, contains about $90 \%$ unsaturated fatty acids and its double bonds per molecule attain 6.6, much higher than those of castor oil (3.0) and soybean oil (4.5). The major fatty acids of SSO are palmitic, stearic, oleic, linoleic and linolenic acids, and the highest percentage is composed of 

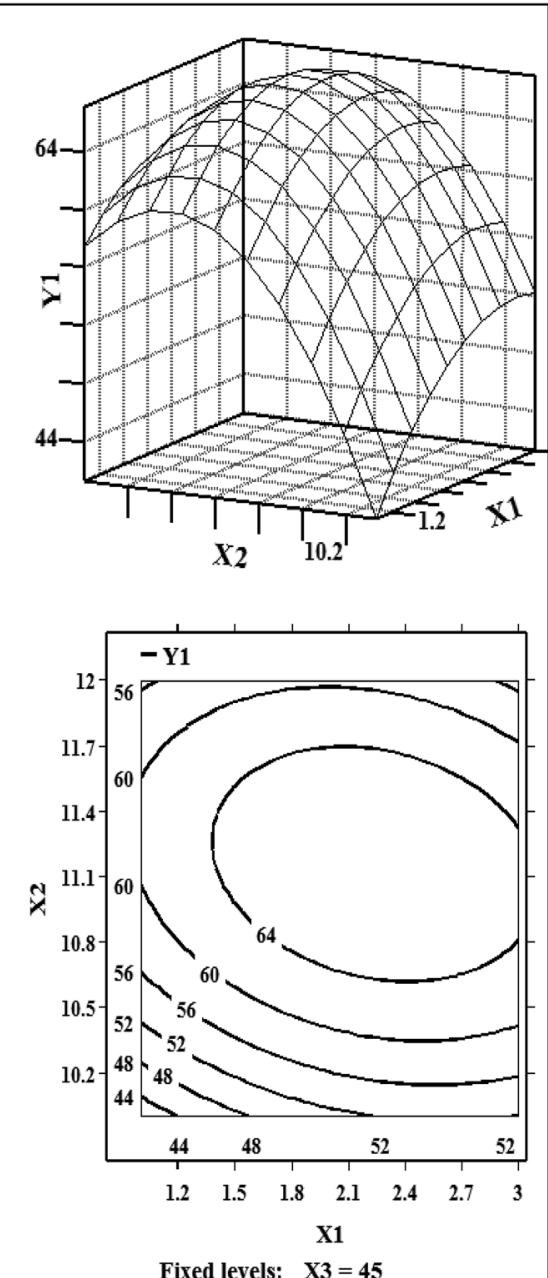

(a)
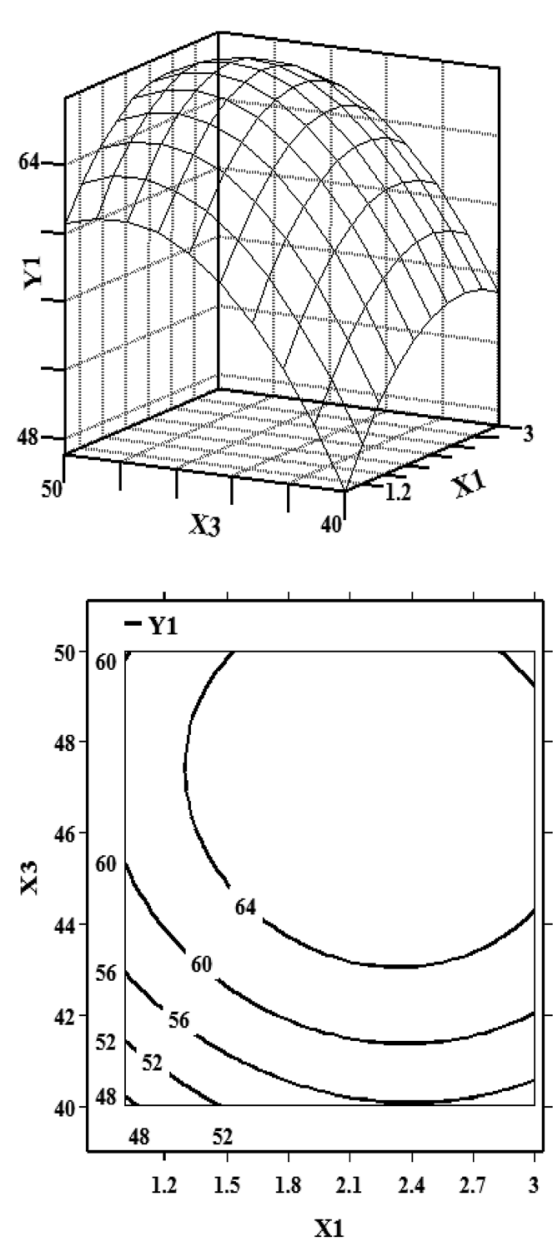

Fixed levels: $\quad \mathrm{X} 2=11$
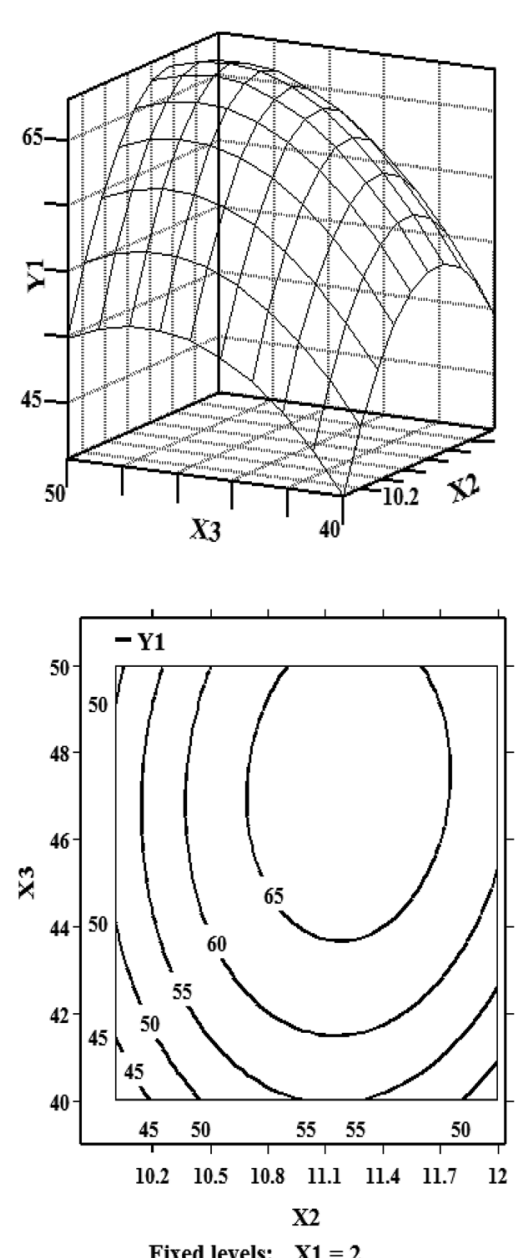

(c)

Fig. 4 Response surface plots and contour plots of interaction between the three independent factors on increased hydroxyl value (a) $X_{1}$ (molar ratio) and $X_{2}$ (reaction time), (b) $X_{1}$ (molar ratio) and $X_{3}$ (reaction temperature), (c) $X_{2}$ (reaction time) and $X_{3}$ (reaction temperature).

linolenic acid (42.7\%), followed by linoleic acid (29.8\%) and oleic acid (14.2\%). ${ }^{12}$ Its iodine value reaches $186.8 \mathrm{~g}$ of $\mathrm{I}_{2} / 100 \mathrm{~g}$, which has a higher iodine value compared with those of other seven plant oils (see Table 5). ${ }^{10}$ Therefore, SSO is one of the most suitable platform chemical materials for different polymer production, such as PUs.

The SSO triglycerides have more than $10 \%$ of saturated fatty acid chains including $7.1 \%$ palmitic $(16: 0)$ and $2.0 \%$ stearic (18:0) fatty acid chains. And the largest non-functional branches on SSO-based polyols synthesized by epoxidation- hydroxylation are the saturated fatty acid branches. These saturated fatty acids reduce the reactivity of SSO-based polyols and affect the final PU properties. ${ }^{18}$ Lipase hydrolysis method can produce the primary alcohol groups in SSO-based polyol and replace the undesirable saturated fatty acid moieties. Furthermore, primary alcohols are usually more reactive with isocyanate than secondary alcohols. Therefore, the high reactivity of primary alcohol groups could improve the formulation of PU synthesis, for example it could reduce catalyst loading, or additive loading in the formulations. ${ }^{7}$

Table 4 The basic characteristic properties of polyol-143 and polyol-211

\begin{tabular}{|c|c|c|c|c|}
\hline Sample & $\begin{array}{l}\text { Hydroxyl value } \\
\text { (mg KOH per g) }\end{array}$ & $\begin{array}{l}\text { Acid value } \\
\text { (mg KOH per g) }\end{array}$ & $\begin{array}{l}\text { Viscosity } \\
\left(25^{\circ} \mathrm{C}\right)\left(\mathrm{mm}^{2} \mathrm{~s}^{-1}\right)\end{array}$ & $\begin{array}{l}M_{\mathrm{w}} \\
\left(\mathrm{g} \mathrm{mol}^{-1}\right)\end{array}$ \\
\hline Polyol-143 & 143 & 1.4 & 2569 & 3010 \\
\hline
\end{tabular}


Table 5 Fatty acids composition (mass\%) and iodine values of common plant oils

\begin{tabular}{|c|c|c|c|c|c|c|}
\hline Name & Palmitic & Stearic & Oleic & Linoleic & Linolenic & $\begin{array}{l}\text { Iodine value } \\
\left(\mathrm{g} \text { of } \mathrm{I}_{2} / 100 \mathrm{~g} \text { ) }\right.\end{array}$ \\
\hline Soybean oil & 14.0 & 4.0 & 23.3 & 52.2 & 5.6 & 128.7 \\
\hline Linseed oil & 5.0 & 4.0 & 22.0 & 17.0 & 52.0 & 180.0 \\
\hline Sunflower oil & 6.5 & 2.0 & 45.4 & 46.0 & 0.1 & 120.2 \\
\hline Peanut oil & 11.6 & 2.2 & 46.5 & 32.2 & - & 97.6 \\
\hline Cottonseed oil & 22.1 & 2.8 & 19.4 & 53.5 & 2.3 & 109.4 \\
\hline Palm oil & 41.8 & 3.4 & 41.9 & 11.0 & - & 43.3 \\
\hline Rapeseed oil & 4.0 & 2.0 & 56.0 & 26.0 & 10.0 & 102.0 \\
\hline Castor oil & 1.5 & 0.5 & 5.0 & 4.0 & 0.5 & 102.2 \\
\hline Corn oil & 10.0 & 4.0 & 34.0 & 48.0 & - & 123.5 \\
\hline SSO & 7.1 & 2.0 & 14.2 & 29.8 & 42.7 & 186.8 \\
\hline
\end{tabular}

3.1.5 FTIR spectra of PU143 and PU211. Representative FTIR spectra of PU143 and PU211 are shown in Fig. 5. The disappearance of the stretching vibration band at $\nu=2270$ $\mathrm{cm}^{-1}$, which corresponds to the -NCO groups of IPDI, suggests that the $-\mathrm{OH}$ groups of the polyols consumed these groups. Moreover, characteristic bands at $\nu=3352 \mathrm{~cm}^{-1}(\mathrm{~N}-\mathrm{H}$ stretching vibration), $1742 \mathrm{~cm}^{-1}$ (carbonyl $\mathrm{C}=\mathrm{O}$ stretching vibration), $1562 \mathrm{~cm}^{-1}(\mathrm{~N}-\mathrm{H}$ out-of-plane bending and $\mathrm{C}-\mathrm{N}$ stretching vibrations), and $1244 \mathrm{~cm}^{-1}$ (ester $\mathrm{C}-\mathrm{O}$ stretching vibration) confirmed the formation of urethane groups $(-\mathrm{NH}-(\mathrm{C}=\mathrm{O})-\mathrm{O}-)$ after the reaction. ${ }^{19}$ The results suggest that PU143 and PU211 had been successfully prepared.

3.1.6 Thermal properties of PU143 and PU211. Fig. 6 presents the TGA and Differential Thermal Gravity (DTG) curves for PU143 and PU211, respectively. In comparison with that of PU143, the TGA curve for PU211 obviously shifted towards higher temperatures. The initial decomposition temperature (IDT) of PU211, which is the temperature at 5\% weight loss, is higher than that of PU143 by $82.6{ }^{\circ} \mathrm{C}$. Thermal degradation of the two PUs takes place in two stages, corresponding to the hard and soft segments, because of thermodynamic incompatibility of these segments of the PU matrix. ${ }^{20}$ The temperatures corresponding to the maximum rate of degradation $\left(T_{\max } \mathrm{S}\right)$ in each of the two stages for PU143 and PU211 are also listed in Fig. 6. In

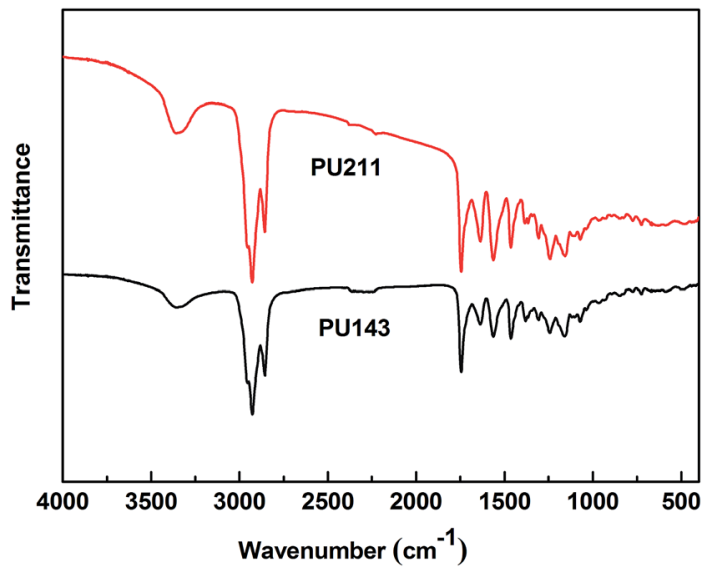

Fig. 5 FTIR spectra of PU143 and PU211. each stage, the thermal degradation temperature of PU211 is significantly higher than that of PU143. The $T_{\max }$ values of PU211 are increased by $78.3{ }^{\circ} \mathrm{C}$ and $97.4{ }^{\circ} \mathrm{C}$ in the respective stages. The results indicate that the thermal stability of PU211 was substantially increased. Saturated fatty acid groups in polyol-143 will reduce its reactivity and affect the properties of the final PU. ${ }^{18}$ Lipase hydrolysis could replace the undesirable saturated fatty acid groups with primary alcohol groups. ${ }^{7}$ Typical polyol-143 has secondary alcohol groups derived from epoxide ring-opening reaction near the middle of the fatty acid chain. However, a polyol bearing secondary alcohol groups is usually less reactive towards isocyanate than a polyol bearing primary alcohol groups. Thus, there is greater reactivity between polyol-211 bearing primary alcohol groups and isocyanate, resulting in better thermal stability of the derived PU211.

DSC curves of PU143 and PU211 are presented in Fig. 7. The $T_{\mathrm{gS}}$ of PU143 and PU211 were determined as $40.9{ }^{\circ} \mathrm{C}$ and $60.6{ }^{\circ} \mathrm{C}$, respectively. Therefore, the $T_{\mathrm{g}}$ value of PU211 was distinctly higher than that of PU143. $T_{\mathrm{g}}$ represents the mobility of polymer chains in the matrix at the molecular level, and an increase therein indicates a decrease in molecular movement in the polymer. ${ }^{21}$ Because polyol-211 with primary alcohol groups bears more hydroxyl groups than polyol-143, it can engage in more chemical interactions with isocyanate, resulting in more

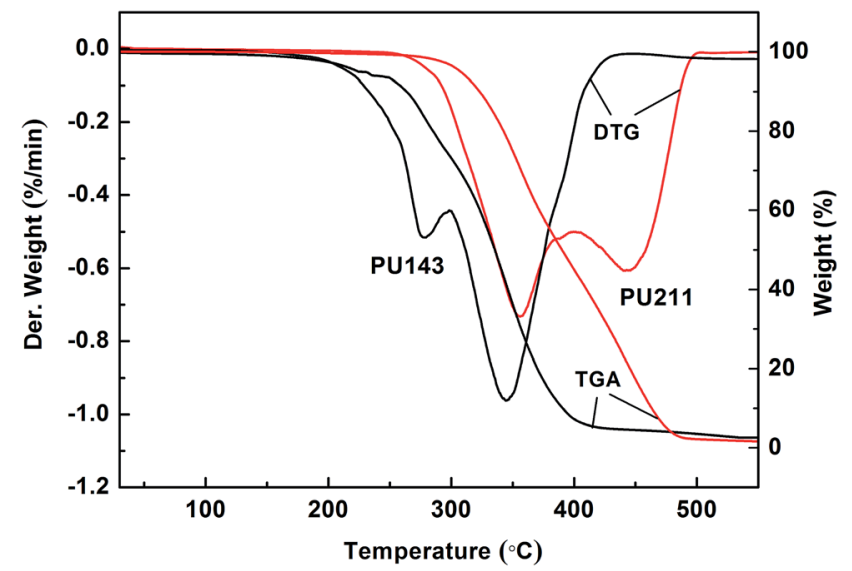

Fig. 6 TGA and DTG curves of PU143 and PU211. 


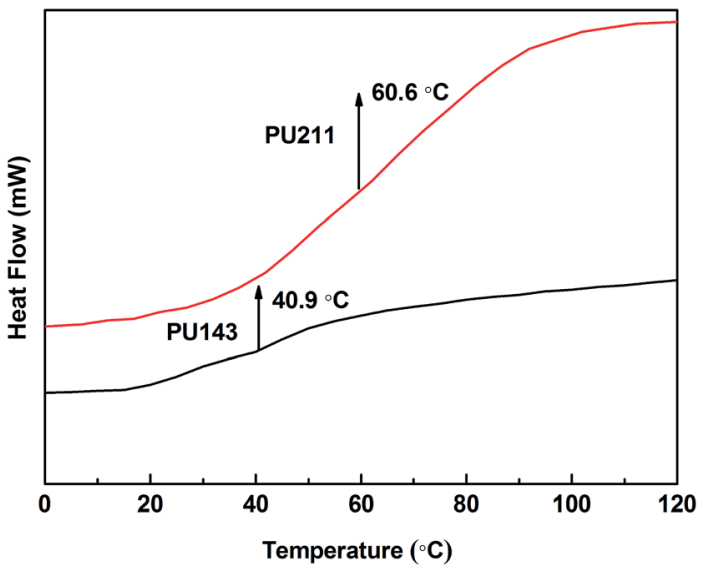

Fig. 7 DSC curves of PU143 and PU211.

Table 6 Mechanical properties of PU143 and PU211

\begin{tabular}{llll}
\hline Sample & $\begin{array}{l}\text { Tensile strength } \\
(\mathrm{MPa})\end{array}$ & $\begin{array}{l}\text { Elongation at } \\
\text { break }(\%)\end{array}$ & $\begin{array}{l}\text { Young's } \\
\text { modulus (MPa) }\end{array}$ \\
\hline PU143 & $3.7 \pm 0.2$ & $293.5 \pm 18.4$ & $10.4 \pm 0.9$ \\
PU211 & $12.5 \pm 0.8$ & $168.3 \pm 13.2$ & $22.3 \pm 2.4$ \\
\hline
\end{tabular}

networks of polymer molecules and a higher $T_{\mathrm{g}}$ for PU211 compared with those for PU143. The increase in $T_{\mathrm{g}}$ for PU211 corresponds to an improvement in its mechanical properties, such as tensile strength and modulus.

3.1.7 Mechanical properties of PU143 and PU211. Tensile strength, Young's modulus, and elongation at break determined for PU143 and PU211 are summarized in Table 6. Compared with PU143, PU211 has 238\% higher tensile strength and $114 \%$ larger Young's modulus. These results are also in accordance with the $T_{\mathrm{g}}$ values. It is because PU211 prepared from polyol-211 with primary alcohol groups forms more crosslinked networks than PU143, leading to higher density. ${ }^{22}$ The obtained polyol-143 by epoxidation-hydroxylation contains more saturated fatty acids, and these inactive regions belong to the category of pendant chains. Pendant chains of the resulting
PU networks represent imperfections in the chemical structure and act as plasticizers that reduce polymer rigidity and improve polymer flexibility. ${ }^{23,24}$ They may be introduced into the polymer network due to incomplete cross-linking reactions, or the presence of monofunctional monomers. ${ }^{25}$ Because of more pendant chains on the polymer molecules, PU143 has a higher elongation at break, compared with PU211.

Table 7 presents the thermal and mechanical properties of the PUs from SSO and other plant oils, such as soybean oil, ${ }^{26}$ linseed oil, ${ }^{27}$ sunflower oil,${ }^{28}$ cottonseed oil,${ }^{29}$ palm oil,${ }^{30}$ rapeseed oil, ${ }^{31}$ castor oil,${ }^{32}$ peanut oil and corn oil. ${ }^{33}$ The properties of PUs depend on the reactivity of plant oils, the properties of fatty acids, and their relative percentages. ${ }^{34}$ Table 7 lists the properties of SSO-based PU synthesized by epoxidationhydroxylation and lipase hydrolysis, such as thermal stability, tensile strength and elongation at break, which are well matched with other types of plant-oil-PUs. Furthermore, DSC results illustrate $T_{\mathrm{g}}$ value of SSO-based PU211 is higher than that of other plant-oil-PUs. The rich hydroxyl numbers and primary alcohol groups of the polyol result in the higher crosslinking density in SSO-based PU211 chemical structure, which can benefit its properties.

\section{Conclusion}

After epoxidation-hydroxylation of SSO to generate polyol-143, a single-factor design and RSM design methodology have been applied to optimize the lipase-catalyzed modification of polyol-143 to increase the number of primary alcohol groups. The results show good consistency between the predicted and experimental values, and $R^{2}=98.68 \%$ demonstrates a high significance for the regression model. The best result in terms of hydroxyl value of the modified polyol reached $211 \mathrm{mg} \mathrm{KOH}$ per $\mathrm{g}$ under optimal conditions of a molar ratio of $\mathrm{H}_{2} \mathrm{O}$ to polyol143 of $2.2: 1$, a reaction time of $11.2 \mathrm{~h}$, and a reaction temperature of $47.2{ }^{\circ} \mathrm{C}$. Furthermore, two PUs have been synthesized from the obtained SSO-based polyols and IPDI by in situ polymerization. Characterization results revealed that the $T_{\mathrm{g}}$ of PU211 derived from the modified polyol-211 was $60.6^{\circ} \mathrm{C}$ and its IDT was $307.2^{\circ} \mathrm{C}$, as compared to respective values of $40.9^{\circ} \mathrm{C}$ and $224.6^{\circ} \mathrm{C}$ for PU143 derived from polyol-143 directly

Table 7 Properties comparison of synthesized PUs from common plant oils

\begin{tabular}{|c|c|c|c|c|c|c|}
\hline \multirow[b]{2}{*}{ Sample } & \multirow[b]{2}{*}{$T_{\mathrm{g}}\left({ }^{\circ} \mathrm{C}\right)$} & \multicolumn{3}{|l|}{ TGA } & \multirow{2}{*}{$\begin{array}{l}\text { Tensile strength } \\
(\mathrm{MPa})\end{array}$} & \multirow{2}{*}{$\begin{array}{l}\text { Elongation at } \\
\text { break }(\%)\end{array}$} \\
\hline & & IDT $\left({ }^{\circ} \mathrm{C}\right)$ & $T_{\max 1}\left({ }^{\circ} \mathrm{C}\right)$ & $T_{\max 2}\left({ }^{\circ} \mathrm{C}\right)$ & & \\
\hline Soybean oil & 20.9 & 242 & - & - & $4.5 \pm 0.6$ & $329.6 \pm 47.2$ \\
\hline Linseed oil & 35.9 & 150 & 267 & 312 & $3.8 \pm 1$ & $256 \pm 6$ \\
\hline Sunflower oil & 41 & - & 284 & 408 & $23.18 \pm 0.8$ & $750 \pm 5$ \\
\hline Peanut oil & -9.2 & - & - & - & $2.27 \pm 0.03$ & $343 \pm 10$ \\
\hline Cottonseed oil & - & - & - & - & $3.26 \pm 0.50$ & $2.44 \pm 0.27$ \\
\hline Palm oil & 39.7 & 191.9 & 275 & 447 & $1.5 \pm 0.3$ & - \\
\hline Rapeseed oil & 43.9 & 256 & 282 & 423 & $11.7 \pm 0.8$ & $420 \pm 10$ \\
\hline Castor oil & -40.2 & 281 & 354 & 434 & $6.3 \pm 0.3$ & $389.1 \pm 12.3$ \\
\hline Corn oil & -6.6 & - & - & - & $3.40 \pm 0.23$ & $322 \pm 12$ \\
\hline SSO & 60.6 & 307.2 & 356.7 & 443.1 & $12.5 \pm 0.8$ & $168.3 \pm 13.2$ \\
\hline
\end{tabular}


generated by epoxidation-hydroxylation. The tensile strength and Young's modulus were also enhanced by $238 \%$ and $114 \%$, respectively. This was because of the more extensive crosslinking networks in PU211 as compared to PU143 due to the higher reactivity of modified polyol-211 bearing primary alcohol groups introduced by lipase-catalyzed hydrolysis.

\section{Acknowledgements}

This work was financially supported by the National Natural Science Foundation of China (No. 31170078), the National High Technology Research and Development Program of China (No. 2011AA02A204 and 2013AA065805), the Natural Science Foundation of Hubei Province (No. 2015CFA085), and the Fundamental Research Funds for HUST (No. 2014NY007 and 2014QN119). We are indebted to the staff of the Analytical and Testing Center of HUST for their valuable assistance in obtaining the FTIR, TGA, and DSC measurements.

\section{References}

1 M. Desroches, M. Escouvois, R. Auvergne, S. Caillol and B. Boutevin, Polym. Rev., 2012, 52, 38-79.

2 A. Zlatanić, C. Lava, W. Zhang and Z. S. Petrović, J. Polym. Sci., Part B: Polym. Phys., 2004, 42, 809-819.

3 P. P. Kiatsimkul, G. J. Suppes, F. H. Hsieh, Z. Lozada and Y. C. Tu, Ind. Crops Prod., 2008, 27, 257-264.

4 Y. Y. Gao, W. W. Chen, H. Lei, Y. Liu, X. Lin and R. Ruan, Biomass Bioenergy, 2009, 33, 277-282.

5 A. E. Atabani, A. S. Silitonga, H. C. Ong, T. M. I. Mahlia, H. H. Masjuki, I. A. Badruddin and H. Fayaz, Renewable Sustainable Energy Rev., 2013, 18, 211-245.

6 A. L. Ahmad, N. H. M. Yasin, C. J. C. Derek and J. K. Lim, Renewable Sustainable Energy Rev., 2011, 15, 584-593.

7 P. P. Kiatsimkul, G. J. Suppes and W. R. Sutterlin, Ind. Crops Prod., 2007, 25, 202-209.

8 C. Ke, X. Li, S. Huang, L. Xu and Y. Yan, RSC Adv., 2014, 4, 57810-57818.

9 P. P. Kiatsimkul, W. R. Sutterlin and G. J. Suppes, J. Mol. Catal. B: Enzym., 2006, 41, 55-60.

$10 \mathrm{G} . \mathrm{Wu}, \mathrm{X} . \mathrm{He}, \mathrm{L} . \mathrm{Xu}, \mathrm{H}$. Zhang and Y. Yan, RSC Adv., 2015, 5, 27097-27106.

11 G. E. P. Box and K. B. Wilson, J. R. Stat. Soc. Series B Stat. Methodol., 1951, 13, 1-45.

12 G. Wu, Y. Fan, X. He and Y. Yan, $R S C A d v .$, 2015, 5, 8089380900 .
13 X. Yao, G. Wu, L. Xu, H. Zhang and Y. Yan, RSC Adv., 2014, 4, 31062-31070.

14 Y. Fan, G. Wu, F. Su, K. Li, L. Xu, X. Han and Y. Yan, Fuel, 2016, 178, 172-178.

15 S. H. Krishna and N. G. Karanth, Catal. Rev.: Sci. Eng., 2002, 44, 499-591.

16 D. G. Hayes, K. D. Carlson and R. Kleiman, J. Oil Fat Ind., 1996, 73, 1113-1119.

17 M. A. Mosiewicki and M. I. Aranguren, Eur. Polym. J., 2013, 49, 1243-1256.

18 Z. S. Petrović, A. Wei Zhang and I. Javni, Biomacromolecules, 2005, 6, 713-719.

19 C. Wang, X. Chen, H. Xie and R. Cheng, Composites, Part A, 2011, 42, 1620-1626.

20 A. K. Barick and D. K. Tripathy, Mater. Sci. Eng., B, 2011, 176, 1435-1447.

21 J. Wang and H. Xie, Soft Matter, 2005, 1, 962-964.

22 X. Kong, G. Liu, H. Qi and J. M. Curtis, Prog. Org. Coat., 2013, 76, 1151-1160.

23 K. Dusek, Macromolecules, 1984, 17, 716-722.

24 Y. L. Lee, P. H. Sung, H. T. Liu, L. C. Chou and W. H. Ku, J Appl. Polym. Sci., 1993, 49, 1013-1018.

25 A. Zlatanić, Z. S. Petrović and K. Dusek, Biomacromolecules, 2002, 3, 1048-1056.

26 Y. Lu, Y. Xia and R. C. Larock, Prog. Org. Coat., 2011, 71, 336342.

27 C. W. Chang and K. T. Lu, Prog. Org. Coat., 2013, 76, 10241031.

28 B. Das, U. Konwar, M. Mandal and N. Karak, Ind. Crops Prod., 2013, 44, 396-404.

29 Z. He, D. C. Chapital, H. N. Cheng, K. T. Klasson, O. M. Olanya and J. Uknalis, Ind. Crops Prod., 2014, 61, 398-402.

30 K. Haji, Biobased Polyurethane from Palm Kernel Oil-Based Polyol, 2012.

31 A. Fridrihsone, U. Stirna, B. Lazdiņa, M. Misāne and D. Vilsone, Eur. Polym. J., 2013, 49, 1204-1214.

32 T. Gurunathan, S. Mohanty and S. K. Nayak, Prog. Org. Coat., 2015, 80, 39-48.

33 T. F. Garrison, M. R. Kessler and R. C. Larock, Polymer, 2014, 55, 1004-1011.

34 M. R. Islam, M. D. H. Beg and S. S. Jamari, J. Appl. Polym. Sci., 2014, 131, 9016-9028. 